\title{
Hyaluronan Hydrogels for Injection in Superficial Dermal Layers: An In Vitro Characterization to Compare Performance and Unravel the Scientific Basis of Their Indication
}

\author{
Annalisa La Gatta ${ }^{1, *}$, Maria Aschettino ${ }^{1}$, Antonietta Stellavato ${ }^{1}$, Antonella D'Agostino ${ }^{1}$, Valentina Vassallo ${ }^{1}$, \\ Emiliano Bedini $^{2}\left(\mathbb{D}\right.$, Gilberto Bellia $^{3}(\mathbb{D})$ and Chiara Schiraldi ${ }^{1, *}$ (D)
}

1 Department of Experimental Medicine, School of Medicine, University of Campania Luigi Vanvitelli, Via L. De Crecchio 7, 80138 Naples, Italy; maryaschettino75@gmail.com (M.A.); antonietta.stellavato@unicampania.it (A.S.); antonella.dagostino@unicampania.it (A.D.); valentina.vassallo@unicampania.it (V.V.)

2 Department of Chemical Sciences, University of Naples Federico II, Complesso Universitario Monte S. Angelo, Via Cintia 4, 80126 Naples, Italy; ebedini@unina.it

$3 \quad$ IBSA Farmaceutici Italia, 26900 Lodi, Italy; gilberto.bellia@ibsa.it

* Correspondence: annalisa.lagatta@unicampania.it (A.L.G.); chiara.schiraldi@unicampania.it (C.S.)

Citation: La Gatta, A.; Aschettino, M.; Stellavato, A.; D'Agostino, A.; Vassallo, V.; Bedini, E.; Bellia, G.; Schiraldi, C. Hyaluronan Hydrogels for Injection in Superficial Dermal

Layers: An In Vitro Characterization to Compare Performance and Unravel the Scientific Basis of Their Indication. Int. J. Mol. Sci. 2021, 22 6005. https://doi.org/10.3390/ ijms22116005

Academic Editor: Marcel Popa

Received: 9 March 2021

Accepted: 28 May 2021

Published: 2 June 2021

Publisher's Note: MDPI stays neutra with regard to jurisdictional claims in published maps and institutional affiliations.

Copyright: (c) 2021 by the authors. Licensee MDPI, Basel, Switzerland. This article is an open access article distributed under the terms and conditions of the Creative Commons Attribution (CC BY) license (https:// creativecommons.org/licenses/by/ $4.0 /)$

\begin{abstract}
Background: Skinboosters represent the latest category of hyaluronan (HA) hydrogels released for aesthetic purposes. Different from originally developed gels, they are intended for more superficial injections, claiming a skin rejuvenation effect through hydration and possibly prompting biochemical effects in place of the conventional volumetric action. Here, three commercial skinboosters were characterized to unravel the scientific basis for such indication and to compare their performances. Methods: Gels were evaluated for water-soluble/insoluble-HA composition, rheology, hydration, cohesivity, stability and effect, in vitro, on human dermal fibroblasts towards the production of extracellular matrix components. Results: Marked differences in the insolublehydrogel amount and in the hydrodynamic parameters for water-soluble-HA chains were evidenced among the gels. Hydration, rigidity and cohesivity also varied over a wide range. Sensitivity to hyaluronidases and Reactive Oxygen Species was demonstrated allowing a stability ranking. Slight differences were found in gels' ability to prompt elastin expression and in ColIV/ColI ratio. Conclusions. A wide panel of biophysical and biochemical parameters for skinboosters was provided, supporting clinicians in the conscious tuning of their use. Data revealed great variability in gels behavior notwithstanding the same clinical indication and unexpected similarities to the volumetric formulations. Data may be useful to improve customization of gel design toward specific uses.
\end{abstract}

Keywords: glycosaminoglycans; hyaluronan; dermal filler; hydration; rheological behavior; hyaluronidase; degradation by reactive oxygen species; human dermal fibroblasts

\section{Introduction}

Facial injection of hyaluronan (HA)-based gels for aesthetic purposes is well-established and HA crosslinked with 1,4 butandiolediglycidylether (BDDE), suspended in physiological solution, is generally employed [1-25]. The use of the BDDE-HA hydrogel typically relies on its elastic behavior, high hydrophilicity and improved resistance to hyaluronidase action, compared to unmodified HA. The elastic behavior is responsible for gel capacity to maintain volume while deforming under the stress of facial movements thus assuring a filling, natural-looking effect; network hydrophilicity improves tissue hydration at the injection site while the higher (but not complete) resistance to enzymatic degradation, compared to natural-occurring HA, assures longer in vivo permanence while preserving bio-absorption.

Since the launch of the first products, the suggested clinical use for this type of hydrogels has changed. Volume restoration, based on the gel physical "filling" effect, has been 
considered the main indication for more than two decades $[2,10-14,19,22]$. Considering that gel-projection capacity is related to its stiffness, $\mathrm{G}^{\prime}$ (Storage Modulus) has long been the only parameter considered in selecting the most suitable gel for the specific clinical need. A more recent approach has been extended to the whole fluido-dynamic gel behavior as well as to its sensitivity to enzymatic and radical degradation and to other properties (e.g., hydration capacity, cohesivity) $[1,5-8,14-25]$. All of the latter features are known to contribute to the in vivo effect after injection and/or over time, and they are therefore generally studied to predict relative in vivo performance and to provide clinicians with valuable information to select treatments and optimize outcome [1,5-8,14-25]. Additionally, due to these studies, HA-BDDE gel design has been improving. As a consequence, hydrogels are now tuned towards more specific and differentiated uses to meet diverse clinical needs finally aiming at a full face restoration $[7,8,21,26,27]$. "Skinboosters" are the latest category of HA gels that entered the market. Unlike typical "volumetric" fillers, skinboosters are intended for the injection into more superficial (intradermal vs. deep dermis-periosteum) skin layers and are expected to improve skin appearance and texture rather than performing by a projection effect. Specifically, improvement in skin hydration and elasticity, and possibly a boost in extracellular matrix molecules biosynthesis is claimed after the application of such gels [28-33]. A stretching effect, referring to wrinkle distension from gel hydration, that is anyway filling the volume loss to a certain extent, is also predicted [30].

Former studies and literature report extensively analyzed volumetric gels and compared available formulations, suggesting opportunities toward design optimization, and supporting their appropriate selection and use [1,5-8,14-25]. On the contrary, no similar studies have been carried out so far to scientifically assist this recent "skinboosting" approach. The aim of the study was to assess a panel of biophysical and biochemical features for this specific type of hydrogel. For this purpose, three gels among the currently marketed crosslinked HA-based skinboosters (i.e., Restylane Vital $\left(\mathrm{R}_{\mathrm{V}}\right)$, Juvederm Volite $\left(\mathrm{J}_{\mathrm{V}}\right)$, Viscoderm Hydrobooster $\left(\mathrm{H}_{\mathrm{B}}\right)$ ) were evaluated for their composition in water-soluble/insoluble $\mathrm{HA}$, rheological behavior, hydration capacity, cohesivity, sensitivity to degradation and ability to induce, in vitro, human dermal fibroblasts towards enhanced production of extracellular matrix components. Beyond increasing our knowledge of these gels, results allow the comparison of gel performance. Further, they may shed light on the possible specific features for the HA-BDDE gels to be classified as a skinbooster

\section{Results}

\subsection{Water-Soluble Fraction of Fillers: Quantitative Determination and Hydrodynamic Analysis}

Total HA concentration in each gel is provided by the manufacturer (Table 1). The water-soluble fraction of the biopolymer was quantified here, allowing us to derive the specific composition in water-insoluble/water-soluble HA (Table 1). Water-soluble HA was found in each formulation and in a comparable amount (about $4 \mathrm{mg} / \mathrm{mL} ; p>0.05$ ). As a result of the diverse biopolymer total concentration, the gels significantly differ for the water-insoluble HA content. Specifically, the insoluble HA fraction in $\mathrm{H}_{\mathrm{B}}$ was far higher than the one found in the other gels, up to 2.6 fold higher, compared to $\mathrm{JV}_{\mathrm{V}}$. As for $\mathrm{R}_{\mathrm{V}}$, the insoluble HA content almost doubled compared to $\mathrm{J}_{\mathrm{V}}$.

Table 1. Amount of water-soluble and water-insoluble.

\begin{tabular}{cccc}
\hline HA $(\mathbf{m g} / \mathbf{m L})$ & $\mathbf{R}_{\mathbf{V}}$ & $\mathbf{J V}_{\mathbf{V}}$ & $\mathbf{H}_{\mathbf{B}}$ \\
\hline total & 20 & 12 & 25 \\
\hline Water-soluble & $4.7 \pm 0.6$ & $4.0 \pm 0.6$ & $4.2 \pm 0.9$ \\
\hline Water-insoluble & $15.4 \pm 0.6$ & $8.0 \pm 0.6$ & $20.8 \pm 0.9$ \\
\hline Soluble HA (wt $\%)$ & $23 \pm 3$ & $33 \pm 5$ & $17 \pm 4$ \\
\hline
\end{tabular}

HA in each gel and hydrodynamic parameters for the water-soluble HA fractions as derived from the Size Exclusion Chromatography-Triple Detector-Array (SEC-TDA) analyses. The total HA concentration reported is the value indicated in the product's package insert. 
The SEC-TDA analyses revealed the presence of a $525 \pm 23 \mathrm{kDa} H A$ in $\mathrm{H}_{\mathrm{B}}$ (Table 2). Shorter HA chains, of about $260 \mathrm{kDa} M_{\mathrm{W}}$, were found in $\mathrm{R}_{\mathrm{V}}$ and HA of $\sim 160 \mathrm{kDa}$ was found in $\mathrm{J}_{\mathrm{V}}$. The intrinsic viscosity and the hydrodynamic radius values varied consistently. The $M_{\mathrm{w}} / \mathrm{M}_{\mathrm{n}}$ values suggested for $\mathrm{R}_{\mathrm{V}}$ and, especially $\mathrm{J}_{\mathrm{V}}$ broader distributions compared to $\mathrm{H}_{\mathrm{B}}$ one.

Table 2. Weight average molecular weight $\left(\mathrm{M}_{\mathrm{w}}\right)$, numeric average molecular weight $\left(\mathrm{M}_{\mathrm{n}}\right)$, polydispersity index $\left(\mathrm{M}_{\mathrm{w}} / \mathrm{M}_{\mathrm{n}}\right)$, intrinsic viscosity $([\eta])$ and hydrodynamic radius $\left(\mathrm{R}_{\mathrm{h}}\right)$.

\begin{tabular}{|c|c|c|c|c|c|}
\hline \multirow{2}{*}{ Sample } & \multicolumn{5}{|c|}{ Hydrodynamc Parameters for the Soluble HA Fractions } \\
\hline & $\mathrm{M}_{\mathrm{W}}(\mathrm{kDa})$ & $\mathrm{M}_{\mathrm{n}}(\mathrm{kDa})$ & $\mathbf{M}_{W} / \mathbf{M}_{\mathbf{n}}$ & {$[\eta](\mathrm{dL} / \mathrm{g})$} & $\mathbf{R}_{\mathrm{h}}(\mathrm{nm})$ \\
\hline $\mathbf{R}_{\mathbf{V}}$ & $266 \pm 29$ & $109 \pm 19$ & $2.5 \pm 0.6$ & $5.7 \pm 0.1$ & $26.8 \pm 1.1$ \\
\hline Jv & $161 \pm 21$ & $49 \pm 5$ & $3.3 \pm 0.2$ & $3.4 \pm 0.2$ & $17.9 \pm 1.0$ \\
\hline $\mathbf{H}_{\mathrm{B}}$ & $525 \pm 23$ & $305 \pm 55$ & $1.7 \pm 0.2$ & $7.5 \pm 0.4$ & $37.2 \pm 1.7$ \\
\hline
\end{tabular}

By comparing the Mark-Houwink-Sakurada (MHS) curves (log intrinsic viscosity vs. $\log$ molecular weight) derived for the soluble fractions to the ones obtained for linear HA samples (Figure S1), a lower intrinsic viscosity over all the molecular weight distribution, was found for the analyzed samples, thus indicating a more compact conformation, consistent with modified chains. Thus, we can assert that soluble HA fractions contain BDDE-HA molecules.

\section{2. ${ }^{1} \mathrm{H}$-NMR Analyses}

The ${ }^{1} \mathrm{H}-\mathrm{NMR}$ spectra obtained for the gels are shown in the Supplementary Material (Figure S2). The BDDE/HA (disaccharide unit) molar ratio was quantified by integrating the signal at $\delta 1.6 \mathrm{ppm}$, due to the aliphatic $\left(\mathrm{CH}_{2}\right)_{2}$ moiety of the BDDE molecule, with respect to the HA N-acetyl signal at $\delta 1.9 \mathrm{ppm}$ (ref). The BDDE/HA ratio (mol \%) was 1.1, 7.0 and 9.5 for $R_{V}, J_{V}$ and $H_{B}$ respectively.

\subsection{Hydration Capacity}

Water absorption was measured to compare the gel hydration capacity. Data reported in Figure 1 demonstrated that gels were able to hydrate and, therefore, to expand, when incubated in a physiological medium. This indicated that the commercialized formulations are not at the equilibrium swelling. Specifically, as reported in Figure 1, when allowed to equilibrate in Dulbecco's Phosphate Buffered Saline (PBS), $R_{V}$ almost doubled its volume and $\mathrm{H}_{\mathrm{B}}$ more than tripled it. $\mathrm{J}_{\mathrm{V}}$ showed the lowest hydration extent $\left(p<0.05 \mathrm{vs} . \mathrm{R}_{\mathrm{V}}\right.$ and $p<0.001$ vs. $\left.\mathrm{H}_{\mathrm{B}}\right)$.

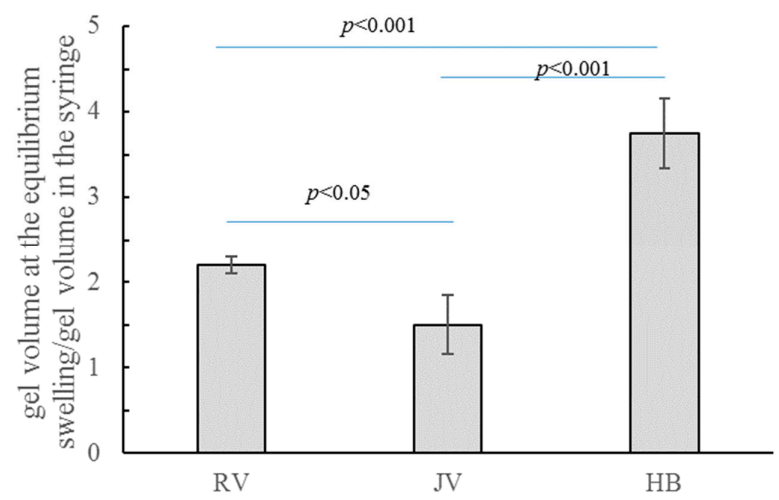

Figure 1. Gels' hydration ability. Volumetric expansion (gel volume at equilibrium/gel volume in the syringe) occurring when the formulations are equilibrated in PBS; data indicate the final volume reached by $1 \mathrm{~mL}$ of the formulations when allowed to hydrate in PBS. 


\subsection{Rheological Parameters}

The rheological characterization confirmed, as expected, an elastic behavior for all the gels, with tan delta values in the range $0.2-0.6$. Further, results indicated that the gels were not comparable for rigidity and, surprisingly, $G^{\prime}$ values varied over a wide range (Figure $2 \mathrm{a}$ ). $\mathrm{R}_{\mathrm{V}}$ 's stiffness was far higher, while $\mathrm{H}_{\mathrm{B}}$ behaved as the less rigid gel. Specifically, $\mathrm{G}^{\prime}$ values at $0.7 \mathrm{~Hz}$ frequency were about $40 \mathrm{~Pa}$ for $\mathrm{H}_{\mathrm{B}}$, about $120 \mathrm{~Pa}$ for $\mathrm{JV}_{\mathrm{V}}$ and as high as $430 \mathrm{~Pa}$ for $\mathrm{R}_{\mathrm{V}}$. The complex viscosity data confirmed the typical profile of this type of hydrogels with values constantly decreasing with frequency. $R_{V}$ behaved as the most viscous gel while $\mathrm{H}_{\mathrm{B}}$ proved the least viscous one (Figure $2 b$ ).

(a)

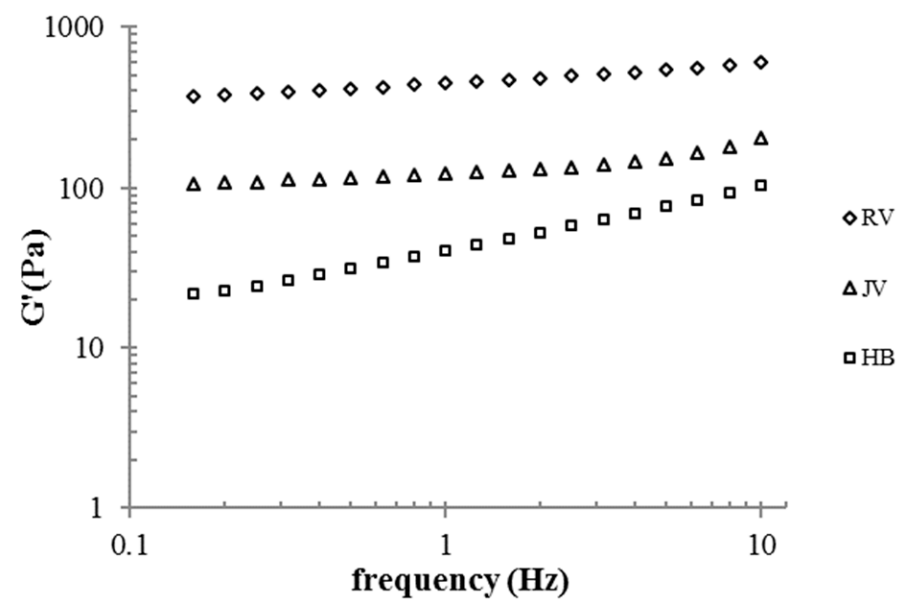

(b)

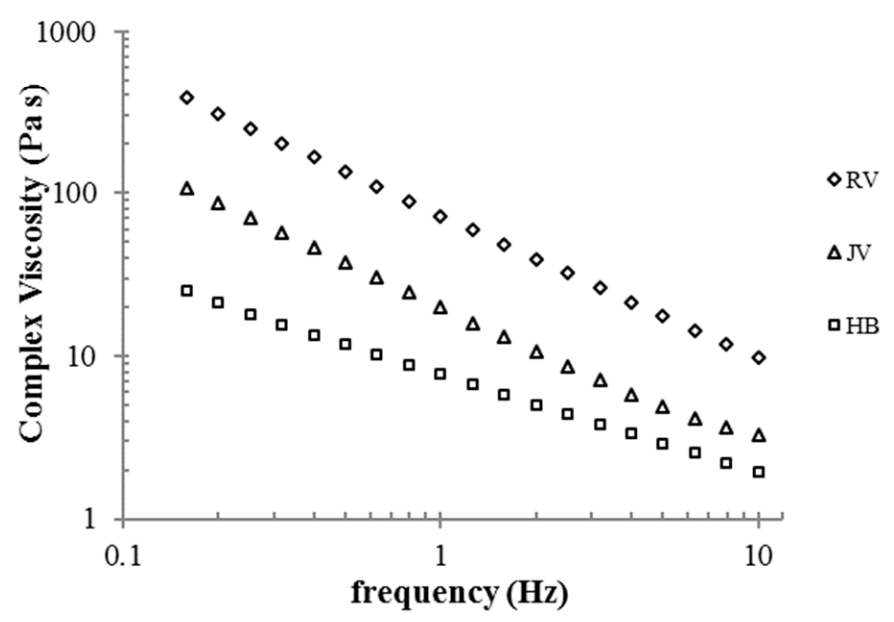

Figure 2. Rheological characterization. $G^{\prime}$ values (a) and complex viscosity (b) as a function of the frequency. Measurements were performed at $37{ }^{\circ} \mathrm{C}$ and $0.1 \%$ strain. 


\subsection{Degradation Studies}

The degradation studies revealed that all the gels were sensitive to both Reactive Oxygen Species (ROS) and Bovine Testicular Hyaluronidase (BTH) action (Figures 3 and 4). Gel sensitivity to ROS was demonstrated by the rheological behavior in the presence of a ROS generating system (Figure 3), compared to a control. Specifically, G' values were recorded during filler incubation with the $\mathrm{H}_{2} \mathrm{O}_{2} / \mathrm{Cu}^{2+}$ system and after diluting the gel, to the same extent, with water (control) (Figure 3a-c). Dilution with water reflected in a 1.1-1.4 fold decrease in $G^{\prime}$ values, compared to the data in Figure 2 and, gel rigidity remained constant over time (Figure 3a-c). In the presence of ROS, a marked drop in $\mathrm{G}^{\prime}$ was observed indicating depolymerization (Figure $\left.3 a-c\right)$. The gels showed diverse degradation profiles. Specifically, $\mathrm{R}_{\mathrm{V}}$ 's stiffness rapidly decreased from about $400 \mathrm{~Pa}$ to values lower than $1 \mathrm{~Pa}$, close to the minimum measurable values, thus causing a scattered signal (Figure 3c). A more gradual reduction in $\mathrm{G}^{\prime}$ was observed for $\mathrm{J}_{\mathrm{V}}$ and for $\mathrm{H}_{\mathrm{B}}$ with the latter degrading faster (Figure 3a,b). In particular, as indicated in Figure 3d, at 2 min of incubation with the ROS generating system, $G^{\prime}$ loss (\% vs. ctr) was already higher than $99 \%$ for $R_{v}$. At the same incubation time, JV still preserved $98 \pm 1 \%$ of its stiffness while, for $\mathrm{H}_{\mathrm{B}}$, around $20 \%$ residual $\mathrm{G}^{\prime}$ was recorded, compared to control. At 5 min of incubation, JV still retained $47 \pm 6 \% \mathrm{G}^{\prime}$; about $93 \% \mathrm{G}^{\prime}$ loss could be measured only at the longer time tested (8 $\mathrm{min})$.

(a)

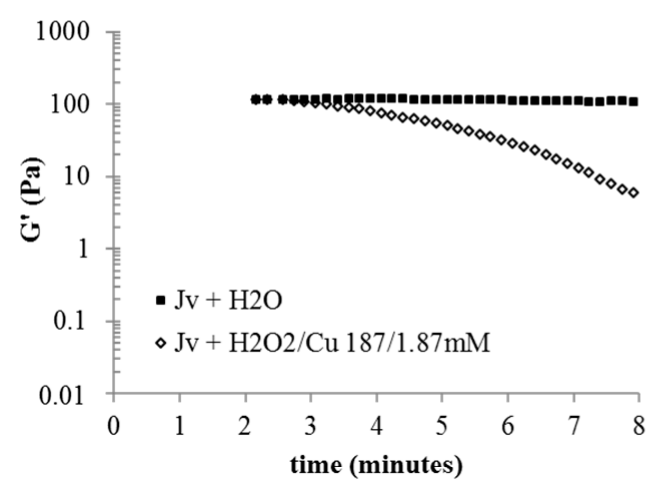

(c)

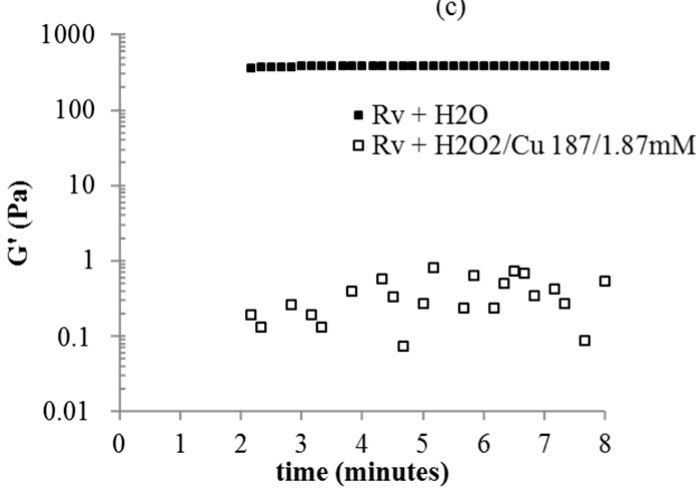

(b)

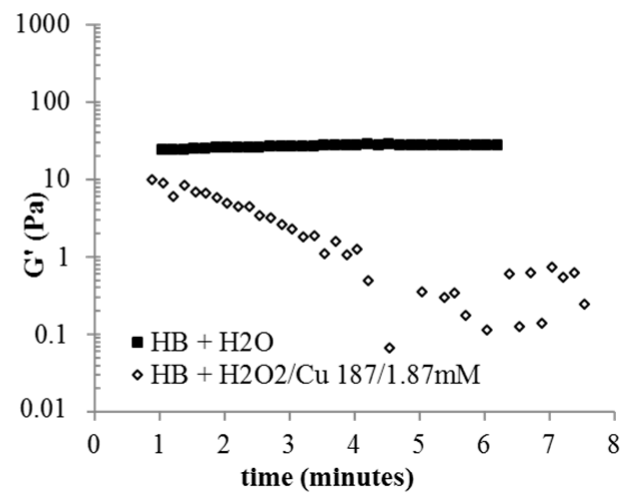

(d)

\begin{tabular}{|c|c|c|c|}
\hline sample & \multicolumn{3}{|c|}{ Residual G' (\%) } \\
\hline & $\begin{array}{c}\mathbf{2} \\
\text { minutes }\end{array}$ & $\begin{array}{c}\mathbf{3 . 5} \\
\text { minutes }\end{array}$ & $\begin{array}{c}\mathbf{5} \\
\text { minutes }\end{array}$ \\
\hline $\mathrm{J}_{\mathrm{V}}$ & $98 \pm 1$ & $79 \pm 5$ & $47 \pm 6$ \\
\hline $\mathrm{H}_{\mathrm{B}}$ & $20 \pm 3$ & $4 \pm 0$ & $\sim 1$ \\
\hline $\mathrm{R}_{\mathrm{V}}$ & $<1$ & $<1$ & $<1$ \\
\hline
\end{tabular}

Figure 3. Degradation in the presence of ROS. $\mathrm{G}^{\prime}$ values during incubation with $\mathrm{H}_{2} \mathrm{O}_{2} / \mathrm{Cu}^{2+} 375 / 3.75 \mathrm{mM}$, compared to a control (gel diluted to the same extent with water) for $\mathrm{J}_{\mathrm{V}}(\mathbf{a}), \mathrm{H}_{\mathrm{B}}(\mathbf{b})$ and $\mathrm{R}_{\mathrm{v}}(\mathbf{c})$. Measurements were performed at $37^{\circ} \mathrm{C}$, $1.59 \mathrm{~Hz}$ frequency and $0.1 \%$ strain. (d) Residual $\mathrm{G}^{\prime}$ (\% in respect to $\mathrm{G}^{\prime}$ for the control) at 2, 3.5 and 5 min of incubation with ROS.

When the gels were incubated in the presence of BTH, a certain extent of HA solubilization was registered for each sample, indicating sensitivity to enzymatic hydrolysis (Figure $4 \mathrm{a}$ ). In particular, around $1 \mathrm{mg} / \mathrm{mL} \mathrm{HA}$ solubilized in $3 \mathrm{~h}$ incubation with BTH $(2 \mathrm{U} / \mathrm{mL}$ ) while the amount rose to $1.2-1.4 \mathrm{mg} / \mathrm{mL}$ when higher enzyme concentration was used $(5 \mathrm{U} / \mathrm{mL} \mathrm{BTH})$ for the same time interval. Under the most drastic hydrolysis 
conditions tested, around $1.7-2.1 \mathrm{mg} / \mathrm{mL}$ of water-soluble fraction increase was recorded. No significant differences in the solubilization extent $(p>0.1)$ could be detected among the gels under the applied conditions, only very slightly lower solubilization of $\mathrm{H}_{\mathrm{B}}$ was recorded under the most drastic conditions. However, based on these solubilization rates and on the initial gels' composition (Table 1). $\mathrm{H}_{\mathrm{B}}$ showed the highest amount of residual water-insoluble $\mathrm{HA}$ during incubation with $\mathrm{BTH}$, regardless of the enzyme concentration and incubation time (Figure $4 \mathrm{~b}$ ).

The hydrodynamic parameters for the soluble fractions obtained after incubation with BTH are reported in Figure 4c. After $3 \mathrm{~h}$ incubation with $2 \mathrm{U} / \mathrm{mL} \mathrm{BTH}$, longer soluble chains were found for $\mathrm{H}_{\mathrm{B}}$ while under the most drastic hydrolysis conditions, slightly lower $M_{\mathrm{W}}$ values were found for $\mathrm{R}_{\mathrm{v}}$. With the increase in $\mathrm{BTH}$ concentration and incubation time, an increase of the HA amount in solution and of polydispersity and a decrease of the $\mathrm{M}_{\mathrm{n}}$ values were recorded.

(a)

\begin{tabular}{|c|c|c|c|}
\hline \multirow{2}{*}{ sample } & \multicolumn{3}{|c|}{$\begin{array}{c}\text { HA }(\mathrm{mg} / \mathrm{mL}) \text { solubilized in the } \\
\text { presence of BTH }\end{array}$} \\
\hline & $\begin{array}{c}2 \mathrm{U} / \mathrm{mL} \\
(3 \mathrm{~h})\end{array}$ & $\begin{array}{l}5 \mathrm{U} / \mathrm{mL} \\
(3 \mathrm{~h})\end{array}$ & $\begin{array}{l}5 \mathrm{U} / \mathrm{mL} \\
(6 \mathrm{~h})\end{array}$ \\
\hline $\mathrm{J}_{\mathrm{V}}$ & $1.0 \pm 0.2$ & $1.5 \pm 0.2$ & $2.1 \pm 0.3$ \\
\hline $\mathrm{R}_{\mathrm{V}}$ & $0.8 \pm 0.1$ & $1.3 \pm 0.1$ & $2.1 \pm 0.1$ \\
\hline $\mathrm{H}_{\mathrm{B}}$ & $0.9 \pm 0.1$ & $1.2 \pm 0.1$ & $1.7 \pm 0.1$ \\
\hline
\end{tabular}

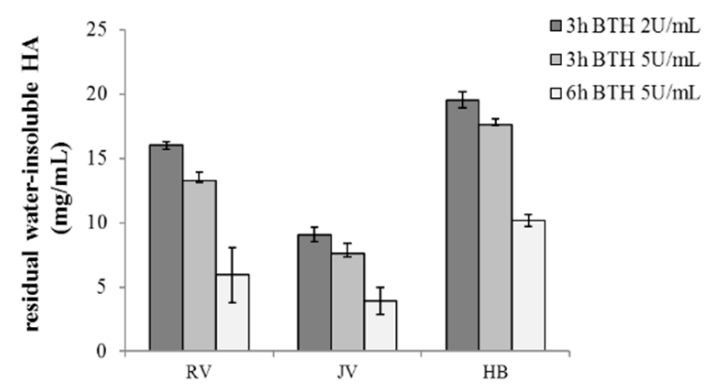

Hydrodynamic parameters for the soluble fraction

watersoluble HA (mg/mL)

$2.3 \pm 0.2$

$2 \mathrm{U} / \mathrm{mL} 3 \mathrm{~h}$

$5 \mathrm{U} / \mathrm{mL} 6 \mathrm{~h}$

$2 \mathrm{U} / \mathrm{mL} 3 \mathrm{~h}$

$5 \mathrm{U} / \mathrm{mL} 6 \mathrm{~h}$

$3.5 \pm 0.4$

$1.8 \pm 0.1$

$3.1 \pm 0.1$

$\mathbf{H}_{\text {B }}$

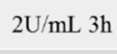

$5 \mathrm{U} / \mathrm{mL} 6 \mathrm{~h}$

$2.4 \pm 0.1$

\begin{tabular}{|r|}
\hline Hyd \\
\hline$M_{w}(\mathrm{kDa})$ \\
\hline
\end{tabular}

$\mathbf{M}_{\mathbf{w}} / \mathbf{M}_{\mathbf{n}}$

\begin{tabular}{|c|c|c|}
\hline $\mathbf{M}_{\mathbf{n}}(\mathbf{k D a})$ & {$[\eta](\mathbf{d L} / \mathbf{g})$} & $\mathbf{R}_{\mathbf{h}}(\mathbf{n m})$ \\
\hline $101 \pm 17$ & $2.3 \pm 0.1$ & $17.1 \pm 0.1$ \\
\hline $60 \pm 10$ & $2.1 \pm 0.3$ & $18 \pm 3$ \\
\hline $103 \pm 14$ & $3.2 \pm 0.0$ & $19.6 \pm 0.4$ \\
\hline $33 \pm 12$ & $2.6 \pm 0.0$ & $16 \pm 1$ \\
\hline $219 \pm 22$ & $5.5 \pm 0.9$ & $31 \pm 3$ \\
\hline $40 \pm 20$ & $3.8 \pm 0.8$ & $21 \pm 4$ \\
\hline
\end{tabular}

Figure 4. Enzymatic degradation. (a) Amount of HA $(\mathrm{mg} / \mathrm{mL})$ solubilized due to the BTH action after $3 \mathrm{~h}$ incubation with BTH $2 \mathrm{U} / \mathrm{mL}$ and after 3 and $6 \mathrm{~h}$ incubation with BTH $5 \mathrm{U} / \mathrm{mL}$. (b) Residual water-insoluble HA (mg/mL) under the same hydrolysis conditions as in (a). (c) SEC-TDA data for the HA water-soluble fraction after $3 \mathrm{~h}$ incubation with $2 \mathrm{U} / \mathrm{mL}$ and $6 \mathrm{~h}$ incubation with BTH $5 \mathrm{U} / \mathrm{mL}$.

\subsection{Cohesivity}

The cohesivity test revealed great differences in gels' behavior. $\mathrm{H}_{\mathrm{B}}$ completely retained its structure in the whole interval time of observation, therefore it was assigned with the highest cohesivity score ("fully cohesive") in the Gavard-Sundaram Cohesivity Scale (Figure 5) proving the most cohesive gel. On the contrary, $\mathrm{J}_{\mathrm{V}}$ progressively completely loses definition behaving as a "fully dispersed" gel (cohesivity score less than 1). An intermediate cohesive behavior was found for $\mathrm{R}_{\mathrm{v}}$ that behaved as a "mostly cohesive" (cohesivity score 4 ) at the early time of observation then showing an increasing extent of fragmentation (cohesivity score 3, "partially cohesive" gel, at 70 and $90 \mathrm{~s}$ of observation). 
(a)

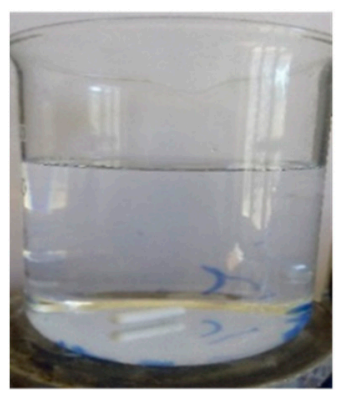

Rv

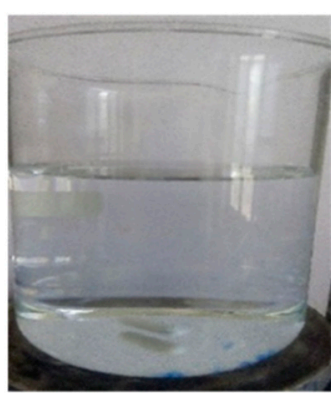

Jv

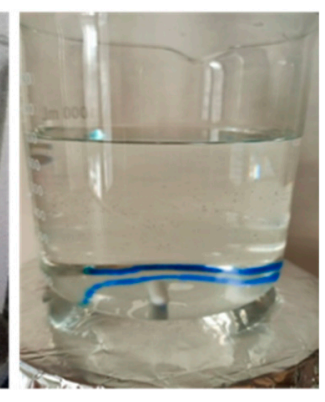

$\mathbf{H}_{\mathbf{B}}$

(b)

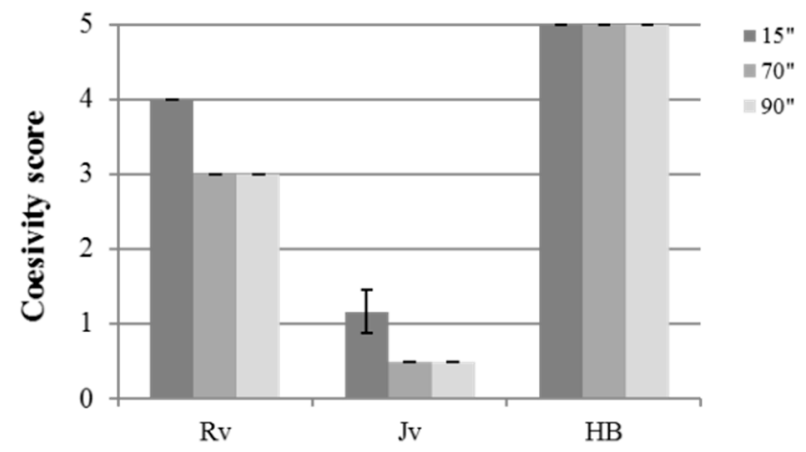

Figure 5. Gel cohesivity. (a) Images of the gels at $15 \mathrm{~s}$ after starting the test. (b) Cohesivity score assigned to the gels at diverse time intervals according to the Gavard-Sundaram Cohesivity Scale [20].

\subsection{Biological Studies}

As shown in Figure 6, the gel treatments on fibroblasts showed the absence of any toxicity. Images of cells after $24 \mathrm{~h}$ incubation with the gels and of untreated cells are shown in Figure 6a. It was evident that fibroblasts in presence of filler, present a very similar morphology to the untreated cells and also the cell density in each well was comparable. Quantitative results on metabolic activity, reported in Figure 6b, confirmed the total absence of cytotoxicity for all the gels.

To elucidate the effect on matrix synthesis due to HA treatments on human dermal fibroblasts, Type I collagen (COLI), type IV collagen (COLIV) and elastin (ELS) gene expression was quantified by qRT-PCR (Figure 7). Overall, the three biomarkers investigated were upregulated, specifically for $\mathrm{H}_{B}$ and $\mathrm{R}_{V}$ with respect to untreated cells. COLI was about 2.5-fold and 1.5-fold expression vs CTR in $\mathrm{H}_{\mathrm{B}}$ and $\mathrm{R}_{\mathrm{V}}$ treated cells. On the contrary, it was down-regulated by JV. COLIV was upregulated by about 3-fold, 4.5-fold and 5-fold expression over the control following $\mathrm{H}_{\mathrm{B}}, \mathrm{J}_{\mathrm{V}}$ and $\mathrm{R}_{\mathrm{V}}$ treatments, respectively (Figure 7). Finally, ELS increased its expression by about 6-fold, 5.8-fold and 3.8-fold expression in fibroblasts treated with $\mathrm{H}_{\mathrm{B}}, \mathrm{J}_{\mathrm{V}}$ and $\mathrm{R}_{\mathrm{V}}$ respectively. Regarding integrins, mRNA expression showed that all samples increased integrins expression (INT $\alpha 1$ and $\beta 1$ ). Specifically, $R_{V}$ upregulated INT $\alpha 1$ by about 4 -fold and INT $\beta 1$ by 3 -fold expression. Instead, INT $\alpha 1$ increased by about 30 -fold and 7 -fold vs. CTR in presence of $\mathrm{J}_{\mathrm{V}}$ and $\mathrm{H}_{\mathrm{B}}$, respectively. While, INT $\beta 1$ mRNA resulted in about a 50 -fold increase vs. CTR for both $\mathrm{J}_{V}$ and $\mathrm{H}_{\mathrm{B}}$, samples. 
(a)
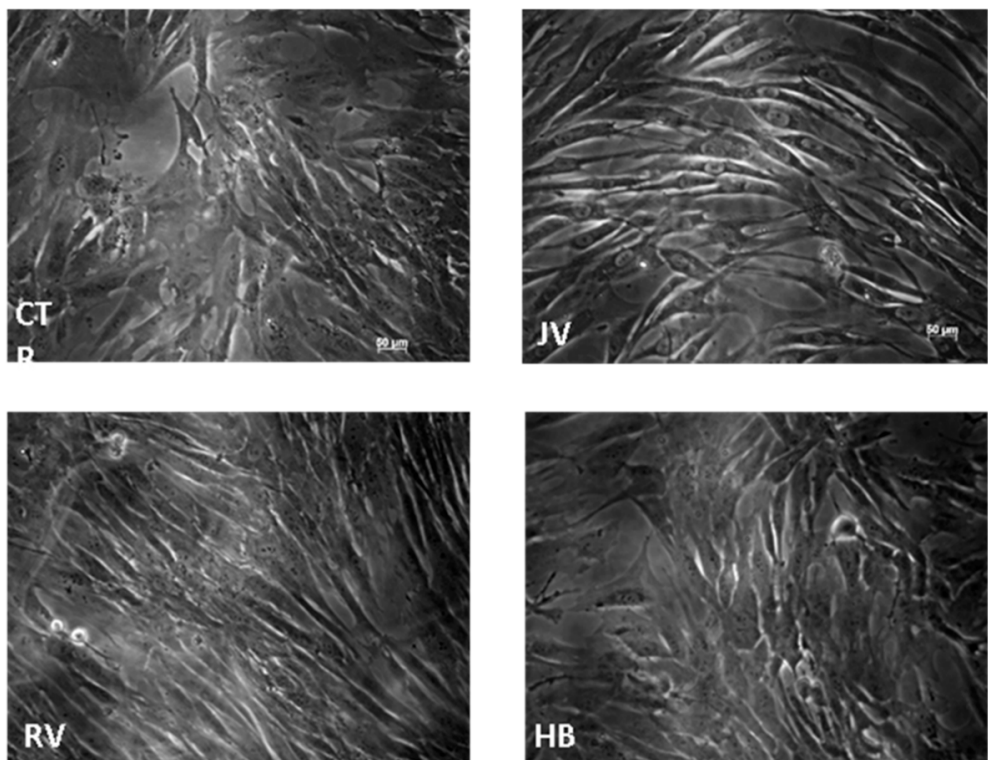

(b)

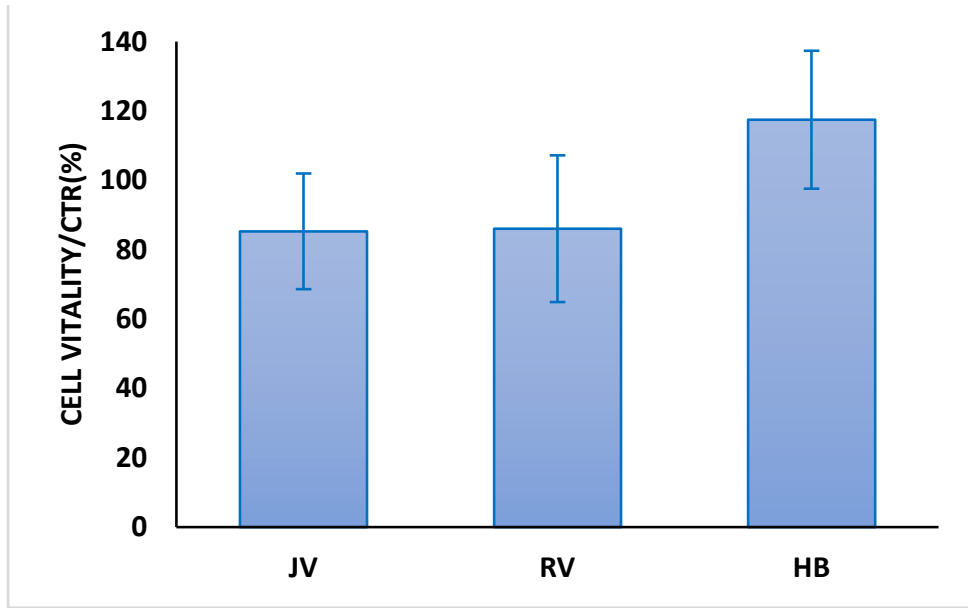

Figure 6. (a) Morphological observation at MO of Human Dermal Fibroblasts (HDF) in the control and in presence of filler, after $24 \mathrm{~h}$ treatment. Scale bar $50 \mu \mathrm{m}$; (b) Cell vitality with respect to the untreated cells in presence of $\mathrm{J}_{\mathrm{V}}, \mathrm{R}_{\mathrm{V}}$ and $\mathrm{H}_{\mathrm{B}}$ respectively.

(a)

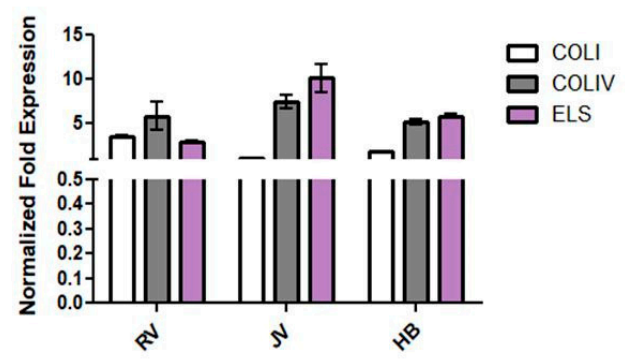

(b)

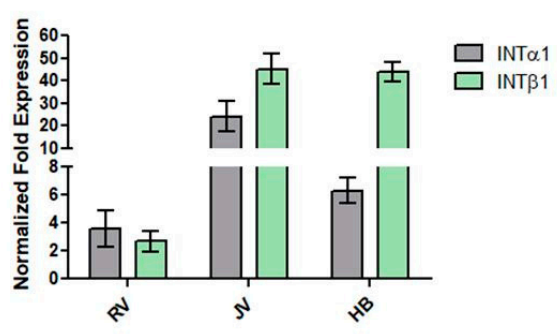

Figure 7. Gene expression analyses: the results are expressed as fold change of HA treated cells respect to untreated cells (CTR) for COLI, COLIV and ELS (a) in human dermal fibroblasts. In addition, INT $\alpha 1$ and $\beta 1(\mathbf{b})$ were accomplished. Data showed as the averages \pm SD. 
At $48 \mathrm{~h}$ of incubation, HDF were lysed to accomplish Western blotting analyses on specific biomarkers. Results are reported in Figure 8 . The graph shows a slight increase in elastin expression in response to $\mathrm{R}_{\mathrm{V}}$ and $\mathrm{H}_{\mathrm{B}}$ treatments (respectively 1.09 and 1.31-fold vs. CTR), the latter proved significant vs. control and $J_{V}$ treatment. $R_{V}$, being less effective than $\mathrm{H}_{B}$ proved superior with respect to elastin biosynthesis in $\mathrm{J}_{V}$ treatment. This latter showed Col I production to a similar extent with respect to the control, while $\mathrm{H}_{\mathrm{B}}$ slightly upregulated its expression (1.20-fold vs. CTR). Finally, the cells treated with $R_{V}$ and $\mathrm{H}_{\mathrm{B}}$ presented a Col IV higher expression in comparison to control and also $\mathrm{JV}_{\mathrm{V}}$ treated cells. Specifically, $\mathrm{R}_{V}$ increased Col IV protein level by about 1.38 -fold vs. CTR and $\mathrm{H}_{B}$ improved it by about 1.52-fold instead, $\mathrm{J}_{\mathrm{V}}$ seemed to be not effective in the modulation of this biomarker.
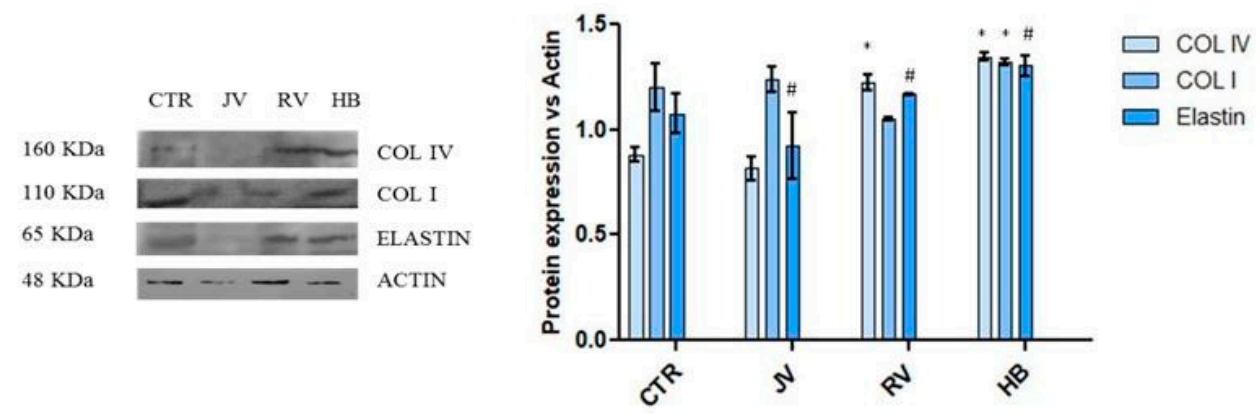

Figure 8. Western blotting for expression of collagen I, collagen IV and Elastin normalized to actin in the densitometry reported as average and SD. ${ }^{*}$ stands for significant $(p<0.05)$ variations respect to CTR, \# stands for $p<0.05$ for elastin expression in HB treatment vs. $\mathrm{R}_{\mathrm{V}}$ and $\mathrm{J}_{\mathrm{V}}$ ones.

\section{Discussion}

Since the first application of hyaluronic acid (HA) injectable implants, the purpose for these treatments has been widened and patients and clinicians now share more consciousness. The final aim of the clinician to satisfy patient expectations without radically changing their face but improving their aspect is obtained by searching for the right product, and the right injection technique within a proposed line of formulations. It has to be considered that the biological diversity of patients and everyday life habits are the major responsible for treatment effectiveness: age, kind of skin, weight loss (or fat compartment), smoking attitude, UV irradiation, have to be considered. However, it has been established that a more precise biophysical description of the HA-based formulations may help in the right product choice according to patient needs. In this respect, scientific evidence has been improving not only to address rheological behavior or chemical aspects (e.g., HA modification degree, molecular weight, etc.) but also biochemical and biological features of the product itself. To this aim, three hyaluronan-based hydrogels were characterized in this research study to bridge the biophysical and biochemical properties to their potential performance as skinboosters and to compare them.

With regard to the gels' composition, according to the labels, the three skinboosters greatly differ in total HA concentration [31-33]. The amount of total HA even doubles from one gel to another. As found for other similar formulations intended for skin rejuvenation, a certain amount of water-soluble HA was present (Tables 1 and 2) [7,8]. In particular, data indicated comparable concentration in soluble HA (about $4 \mathrm{mg} / \mathrm{mL}$ ) among the skinboosters but diverse hydrodynamic parameters. Specifically, $\mathrm{R}_{\mathrm{V}}$ and $\mathrm{J}_{\mathrm{V}}$ soluble $\mathrm{HA}$ chains were more similar in length $\left(160-270 \mathrm{kDa} M_{\mathrm{W}}\right)$ while, the soluble HA fraction in $\mathrm{H}_{\mathrm{B}}$ presented far higher molecular weight ( $525 \mathrm{kDa} M_{\mathrm{W}}$ ), therefore potential diverse biochemical effect could be expected for this gel [34]. For all the samples, the analyses of the MHS curves suggested water-soluble HA chains conformation other than linear thus indicating a certain extent of chemical modification. This is in agreement with previous studies on similar products [15]. Rationally, the water-soluble HA fraction may derive 
from the crosslinking process leaving HA chains that, even if crosslinked/modified, are still soluble in an aqueous medium due to low(er) molecular weight.

Gel composition studies also highlighted, among the skinboosters, a far higher amount of water-insoluble $\mathrm{HA}$ (hydrogel fraction) for $\mathrm{H}_{\mathrm{B}}$ thus suggesting potential different biophysical behavior for this gel. The hydrogel fraction in $\mathrm{H}_{\mathrm{B}}$ was far higher even compared to volumetric gels while, in general, similar or lower water-soluble HA concentrations were found in the skinboosters [7]. Collected data indicated an unexpected similarity (in total HA concentration, composition and soluble HA chains' hydrodynamic parameters) between the "volumetric" and the "skinbooster" Restylane formulations [7]. Even if less concentrated in total HA, insoluble/soluble-HA composition Juvederm skinbooster resulted also similar to the corresponding volumetric gel with comparable hydrodynamic parameters, as well [7].

Data on gel-water uptake support the claimed in vivo tissue hydration effect. The gels were able to absorb water even more than tripling their weight/volume $\left(\mathrm{H}_{\mathrm{B}}\right)$. However, it is worth underlining that $\mathrm{J}_{\mathrm{V}}$ increased its volume only by about $30 \%$ that was unexpected for the pursued application as a skinbooster. This result is peculiar if compared to the water up-take values generally reported for other dermal fillers with volumetric indication (up to $280 \%$ volume increase due to hydration) [7]. $\mathrm{H}_{\mathrm{B}}$ showed water up-take values close to the highest ones reported for volumetric preparations, while the other two skinbooster preparations showed lower hydration ability, even with respect to the volumetric gels. It has to be considered that being injected at a superficial layer, a very high water uptake is undesirable as it may result in edema, which will reduce patient compliance $[21,35]$. However, the products that are proposed for more superficial injections need to be easily spreadable, this will ensure distribution of the gel in a larger area, and the water recall in the tissue will be more physiological. Finally, it is worth underlying that collected data do not directly translate into the fillers relative in vivo expansion at the injection site: compression forces exerted by the surrounding tissue, counteracting gel expansion, should also be considered for a more accurate prediction. The rheological data were also surprising since evidencing a huge difference in rigidity notwithstanding the specific proposed application as skinboosters: more than one order magnitude $G^{\prime}$ variation was measured. Further, while $\mathrm{J}_{V}$ and $\mathrm{H}_{\mathrm{B}}$ rigidity was, as expected, far lower than the one reported for the volumetric dermal fillers, the $G^{\prime}$ value registered for $R_{V}$ was higher than the majority of the volumetric gels and close to the $R_{\text {Lift }}$ stiffness $\left(R_{\text {Lift }}\right.$ is the volumetric gel of the Restylane fillers family) [7]. A low rigidity is associated with high deformability under applied stress, thus reflecting in a reduced or even absent "palpability" of the gels, which is crucial to obtain a natural-looking effect when gels are delivered in superficial skin layers $[8,9,14,36,37]$.

Investigation of gel degradation profile is key since it is related to the in vivo longevity of the gels. All the samples showed sensitivity to BTH and ROS action thus ensuring in vivo resorbability. BTH was selected for this study because of the reported similarities to human hyaluronidases (HAses) [38,39] and because it is commercially available in pure form. BTH action is expected to have two effects: solubilization of the water-insoluble HA hydrogel and hydrolysis of the water-soluble HA chains (reduction of the average molecular weight). Despite the comparable rate of water-insoluble fraction solubilization, when equal volumes of the gels are injected, a longer in situ persistence can be predicted for $\mathrm{H}_{\mathrm{B}}$, while $\mathrm{J}_{\mathrm{V}}$ is expected as the shorter-lasting gel. This is related to the initial differences in total HA amount and insoluble hydrogel fraction that will resist enzymatic degradative conditions, based on the comparable degradation rate. Hydrodynamic analyses revealed that the molecular weight distribution of the soluble HA chains is widened during enzymatic hydrolysis. This is rationally related to the depolymerization of the water-soluble HA chains while progressive solubilization of the hydrogel may be responsible for the passage of longer polymeric chains to the solution. This would also explain the observed variation in the average molecular weight during incubation with the enzyme. The increase in $c / M_{n}$ ratio ( $c$ is the water-soluble polymer concentration $\left(\mathrm{mg} / \mathrm{mL}\right.$ ) and $\mathrm{M}_{\mathrm{n}}$ is the number average 
molecular weight) proves, as expected, the increase in the polymer mol number in solution accompanying BTH action [40].

Data on the rheological behavior of the gels under in vitro oxidative stress conditions indicated markedly diverse sensitivity to ROS action. Specifically, based on collected data, the shorter permanence may be predicted for $R_{V}$ while a more gradual loss of the clinical effect may be expected for $\mathrm{H}_{\mathrm{B}}$ and, finally, $\mathrm{J}_{\mathrm{V}}$ showed the highest resistance.

In vitro degradation studies either with ROS or with BTH serve as support to characterize the gels in comparable situations, however, the two phenomena are contemporary acting in vivo, besides the mechanical stress of face muscle movements, therefore the lifetime of the injected gels may be better derived through in vivo study. However, considering the more superficial delivery for skinboosters, and the intradermal penetration of UV radiation, sensitivity to ROS action, poorly investigated so far, has a key role for the gel stability when injected [41].

Skinboosters showed far lower resistance to ROS action than volumetric gels. Compared to the less sensitive volumetric gel, the most resistant skinbooster retained 50\% rigidity in about the same time interval but in the presence of half the amount of ROS [7].

Cohesivity was recently defined as gel capacity to not dissociate [20]. Dermal fillers are lately investigated for their cohesive behavior referring to the pilot study by Sundaram and collaborators establishing a scale for gel rating [20]. Availability of cohesivity data on commercialized gels is helpful to clinicians in the selection of the most appropriate product to achieve the specific clinical objective. Fillers with higher cohesivity are considered a better choice for more superficial treatment. They allow spreadability and, therefore, a gel homogeneous distribution within the tissue, without fragmentation, thus avoiding palpability and even the eventually occurring formation of nodules $[6,20,21] . \mathrm{H}_{B}$ was the most cohesive. A better tissue integration pattern can be predicted for this gel based on its high cohesivity/low viscosity profile $[6,20,21]$. Results obtained in the framework of this study indicated that, despite the similar indication of use, the skinboosters herecharacterized showed wide variability in terms of cohesivity (from 1 to 5) similar to our previous findings on volumetric preparations [7]. Even if the parameters affecting the gel's cohesivity still need to be fully clarified, the strategy used for HA crosslinking may reasonably have an effect on gel's behavior in this specific analysis.

Soft gels that are aiming at tissue revitalization should improve skin texture besides their effect in filling wrinkles. Their expected lower $G^{\prime}$ and viscosity gives less performance than other gels to fill void volume, but this helps in reducing palpability and the Tyndall effect $[19,21]$. However, it can be argued that a biological effect is desirable beyond the physical effect. For this reason, we studied the gels in contact with human dermal fibroblasts. Data on the metabolic activity of cells, cultured on Tissue Cultured Polystyrene, in the presence of the hydrogels were demonstrated to be consistent with the CE approval of these class III medical devices, with an absence of any toxicity. Biological data showed a slight improvement in key biomarkers for $\mathrm{H}_{\mathrm{B}}$ and $\mathrm{R}_{\mathrm{V}}$ and a lower if none effect for $\mathrm{J}_{V}$. Specifically, elastin expression for $\mathrm{H}_{\mathrm{B}}$ was superior with respect to the other treatments, and ColIV expression with respect to Coll was improved in $\mathrm{R}_{\mathrm{V}}$ and $\mathrm{H}_{\mathrm{B}}$ treatments. Comparison with data obtained for volumetric gels did not reveal a stronger biochemical effect for skinboosters on Coll and elastin production, however, the ratio collagen IV/Col I, besides elastin biosynthesis may support, as the final outcome, an improvement of flexible cutaneous basement membrane structure and, therefore, of skin (dermal tissue) quality and texture.

Biological data obtained on dermal fibroblasts at transcriptional and protein levels proved that lightly crosslinked HA-based gels, aiming at superficial treatments, were able to prompt collagen synthesis. Alteration in the extracellular matrix and especially collagen expression are generally associated with skin aging [42]. In this respect, improved biosynthesis of ECM proteins has a beneficial effect on skin/dermal rejuvenation procedures, besides wrinkles filling, leading to tissue hydration and consistency improvement [43]. It has been reported that integrins play a key function in cell adhesion as signaling receptors, 
acting as a bridge between ECM and cytoskeleton proteins in order to allow cell movement $[44,45]$. Activation of the integrin complex $(\alpha 1 \beta 1)$ by an extracellular ligand (e.g., collagen, laminin and elastin) leads to specific intracellular signaling, involving phosphorylation and dephosphorylation reactions for matrix remodeling [46,47]. Our results allowed us to evaluate a beneficial effect of the analyzed samples on proteins matrix hypothesizing an involvement of the integrins receptor.

Finally, it is here demonstrated that biosynthetic pathways related to extracellular macromolecules are indeed affected by modified HA, even if this aspect was less investigated for these kinds of formulations generally used for their biomechanical effects.

Overall, it is worth underlying that the increasing number of in vitro studies characterizing commercial gels is surely useful to increase clinicians' awareness in the selection and use of these gels and they are even more valuable in case of newly-developed gels for which clinical data are still lacking. However, attention has to be paid to translate these in vitro data to in vivo performance since additional aspects such as the mechanical properties of the tissue surrounding the implanted gel that can affect both hydration and projection capacity of the gels as well as individual inflammatory reactions and other in vivo mechanisms affecting degradation, and biological effect dependence on products in vivo degradation should be also considered.

\section{Materials and Methods}

\subsection{Materials}

Restylane Vital $\left(\mathrm{R}_{\mathrm{V}}\right)$ is $a$ Q-Med AB product (Q-Med AB, Uppsala, Sweden) Juvederm Volite $\left(\mathrm{J}_{\mathrm{V}}\right)$ is distributed by Allergan S.P.A. (Pringy, France). Viscoderm Hydrobooster $\left(\mathrm{H}_{\mathrm{B}}\right)$ is distributed by IBSA Farmaceutici Italia srl (Lodi, Italy). They are HA-based dermal fillers intended for use as skinboosters. They all consist of BDDE-crosslinked HA, suspended in physiological medium. The total HA concentration, as reported in the package inserts, is $20 \mathrm{mg} / \mathrm{mL}$ for $\mathrm{R}_{\mathrm{V}}, 12 \mathrm{mg} / \mathrm{mL}$ for $\mathrm{J}_{\mathrm{V}}$ and $25 \mathrm{mg} / \mathrm{mL}$ for $\mathrm{H}_{\mathrm{B}}$. Bovine testicular hyaluronidase, BTH (EC 3.2.1.35), salt-free lyophilized powder with a specific activity of $890 \mathrm{U} / \mathrm{mg}$ was purchased from Sigma-Aldrich S.R.L. (Milan, Italy) (cat. N.H3884, lot. SLBF8562V). Dulbecco's Phosphate Buffered Saline (PBS) without calcium and magnesium was purchased from Lonza Sales Ltd., Switzerland (cat. N.BE17-516F, lot. N.3MB191). Hydrogen peroxide, $30 \% w / w$ in water was purchased from Sigma Aldrich S.R.L. (Milan, Italy), cat. N.H1009. Copper (II) sulfate ( $\geq 99 \%$ ) Fluka, cat. N.61230, was purchased from Sigma Aldrich S.R.L. (Milan, Italy).

\subsection{Biophysical and Chemical Characterization}

\subsubsection{Soluble Fraction Quantification and Hydrodynamic Characterization}

Filler soluble fraction was quantified as reported elsewhere $[7,8]$. Briefly, each filler was diluted to $4 \mathrm{mg} / \mathrm{mL}$ in PBS (1.0 $\mathrm{mL}$ final volume). The resulting suspension was kept under stirring $(1000 \mathrm{rpm})$ for $24 \mathrm{~h}$ at $37^{\circ} \mathrm{C}$. The sample was then centrifuged at $13,000 \times g$ for $5 \mathrm{~min}$, and the supernatant was removed and filtered on $0.22 \mu \mathrm{m}$. Filtered samples were then quantitatively analysed for the HA content by carbazole. Based on the total HA concentration indicated in the package inserts, the amount of water-insoluble $\mathrm{HA}(\mathrm{mg} / \mathrm{mL})$ in each gel was calculated. Hydrodynamic characterization of gel's soluble fractions was also performed by using the SizeExclusion Chromatography-Triple Detector Array (SECTDA) equipment by Viscotek (Malvern Panalytical). Specifically, several aliquots of filtered samples, obtained as described above, were diluted at concentrations suitable for the chromatographic analysis.

The hydrodynamic parameters for the soluble fraction of the gels were determined by the Size Exclusion Chromatography-Triple Detector Array (SEC-TDA) equipment by Viscotek (Viscotek, Malvern, UK). A detailed description of the SEC-TDA system, of its potential to analyse biopolymers such as HA, and of the analysis conditions are reported elsewhere [40]. Sample's molecular weight $\left(M_{\mathrm{w}}, \mathrm{M}_{\mathrm{n}}, M_{\mathrm{w}} / \mathrm{M}_{\mathrm{n}}\right)$, molecular size (hydro- 
dynamic radius $-\mathrm{R}_{\mathrm{h}}$ ) and intrinsic viscosity $([\eta])$ distributions were derived. The MarkHouwink-Sakurada (MHS) curve $\left(\log [\eta]\right.$ vs. $\left.\log M_{\mathrm{W}}\right)$ was directly derived for each sample.

\subsection{2. ${ }^{1} \mathrm{H}-\mathrm{NMR}$ Analyses}

Gels were investigated for the BDDE/HA content by ${ }^{1} \mathrm{H}-\mathrm{NMR}$, as previously described, with slight modifications [25]. Briefly, gels were diluted to $4 \mathrm{mg} / \mathrm{mL}$ in $\mathrm{HCl} 0.01 \mathrm{M}$ and incubated for $72 \mathrm{~h}$ at $70{ }^{\circ} \mathrm{C}$ under stirring ( $400 \mathrm{rpm}$ ). The samples were neutralized by adding $\mathrm{Na}_{2} \mathrm{HPO}_{4}$ and lyophilized. The dried samples were dissolved in $\mathrm{D}_{2} \mathrm{O}$ and ${ }^{1} \mathrm{H}-\mathrm{NMR}$ analyses were performed using a Bruker DRX-400 ( ${ }^{1} \mathrm{H}$ NMR: $\left.400 \mathrm{MHz}\right)$ instrument at $298 \mathrm{~K}$. Data were processed using the data analysis packages integrated with Bruker TopSpin ${ }^{\circledR}$ 4.0.5 software.

\subsubsection{Hydration Capacity}

Gels were diluted to $4 \mathrm{mg} / \mathrm{mL}$ in PBS and incubated overnight in thermoshaker at $37^{\circ} \mathrm{C}$ under stirring for $16 \mathrm{~h}$. After centrifugation $(13,000 \times \mathrm{g}, 5 \mathrm{~min})$ and supernatant removal, the pellet was weighed obtaining the hydrated sample mass (g), corresponding to the hydrated sample volume $(\mathrm{mL})$ (density equal to $1 \mathrm{~g} / \mathrm{mL}$ ). The hydration extent of each gel was calculated as:

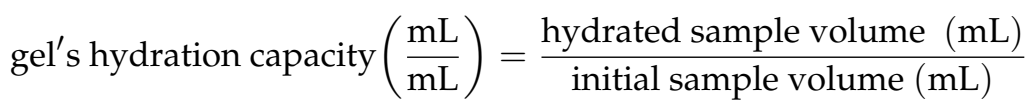

Such values represent the volume expansion for each formulation when allowed to reach the equilibrium swelling in PBS.

\subsubsection{Rheological Characterization}

Rheological measurements were performed as reported elsewhere $[7,8]$ with slight modifications. A Physica MCR301 oscillatory rheometer (Anton Paar, Ostfildern, Germany) equipped with a parallel plate geometry, $25 \mathrm{~mm}$ plate diameter $\left(\mathrm{R}_{\mathrm{V}}, \mathrm{J}_{\mathrm{V}}\right)$ and $50 \mathrm{~mm}\left(\mathrm{H}_{\mathrm{B}}\right)$, and Peltier temperature control was used. Measurements were performed at $37^{\circ} \mathrm{C}$. Oscillation frequency sweep tests were carried out over a frequency range from 0.159 to $10 \mathrm{~Hz}$ (a range of frequencies considered physiologically relevant for the specific application), at a constant strain selected within the linear viscoelastic range $(0.1 \%)$. $\mathrm{G}^{\prime}$ and $\mathrm{G}^{\prime \prime}$ were measured and reported as a function of frequency. Complex viscosity values were also registered in the frequency range exploited. Representative curves are reported.

\subsubsection{Stability to Degradation}

Gels were evaluated for their sensitivity to degradation due to ROS- and BTH-action.

Stability of the gels to ROS action was studied using the $\mathrm{H}_{2} \mathrm{O}_{2} / \mathrm{Cu}^{2+}$ system for generating radicals. Experiments were carried out as previously reported, with minor modification [7]. Briefly, aqueous solutions of $\mathrm{H}_{2} \mathrm{O}_{2}$ and $\mathrm{CuSO}_{4}$ were added to each gel to have $\mathrm{H}_{2} \mathrm{O}_{2} 187 \mathrm{mM}$ and $\mathrm{CuSO}_{4} 1.87 \mathrm{mM}$ while diluting the gel 1:1.3 $(w / w)$. The suspensions were mixed and rapidly placed on the lower plate of the rheometer. A PP25 geometry, (25 mm plate diameter) was used. A time oscillatory test was carried out at $37^{\circ} \mathrm{C}$. Specifically, the storage modulus value of the samples was measured as a function of the time while maintaining constant the frequency $(1.59 \mathrm{~Hz})$ and the strain $(0.1 \%)$. The delay between the addition of the $\mathrm{H}_{2} \mathrm{O}_{2} / \mathrm{Cu}^{2+}$ system to the samples and the acquisition of the first $\mathrm{G}^{\prime}$ value was 1-3 min. For each gel, the same experiment was performed adding water in place of the $\mathrm{H}_{2} \mathrm{O}_{2} / \mathrm{Cu}^{2+}$ system (control). Degradation was monitored by measuring the $\mathrm{G}^{\prime}$ decrease (\% in respect to the control) as a function of the incubation time (up to $8^{\prime}$ ) with the ROS generating system. Experiments were carried out in duplicate.

Sensitivity of the gels to enzymatic degradation was evaluated as previously reported with slight modification $[7,8,25]$. Specifically, the amount $(\mathrm{mg} / \mathrm{mL})$ of HA solubilized due to BTH action was determined as a measure of degradation. Gels were diluted in PBS to $4 \mathrm{mg} / \mathrm{mL}$ final concentration and incubated in the presence of BTH $2 \mathrm{U} / \mathrm{mL}(3 \mathrm{~h})$ and 
$5 \mathrm{U} / \mathrm{mL}\left(3 \mathrm{~h}\right.$ and $6 \mathrm{~h}$ ) at $37^{\circ} \mathrm{C}$ under stirring. Testing was interrupted by boiling the sample for $10 \mathrm{~min}$ to inactivate the enzyme. Samples were then centrifuged at $13,000 \times g$ for 5 min. The supernatant was removed, filtered on $0.22 \mu \mathrm{m}$, opportunely diluted in water and then quantitatively analyzed for the HA content by carbazole assay. The amount of soluble HA already existing in the gel (determined as indicated in Section 4.2.1) was subtracted to obtain the amount of HA solubilized due to BTH action. Further, the watersoluble fraction derived from the less and the most drastic enzymatic hydrolysis conditions tested underwent hydrodynamic characterization using the SEC-TDA system (see also Section 4.2.1).

\subsubsection{Cohesivity}

Product cohesivity was evaluated following the validated protocol reported by Sundaram and collaborators [20]. Specifically, $1 \mathrm{~mL}$ of gel was stained with $10 \mu \mathrm{L}$ of toluidine blue $(0.1 \%)$ and filled in a $1 \mathrm{~mL}$ syringe. The sample was extruded in a $1 \mathrm{~L}$ beaker with $700 \mathrm{~mL}$ of water $\mathrm{mQ}$, while stirring $(160 \mathrm{rpm})$ with the aid of the magnetic stirred $(2.5 \mathrm{~cm})$. Photos at diverse time intervals and videos were taken. Cohesivity was evaluated independently by 4 raters that assigned, for each sample, at each time, a value of cohesivity (from 1 to 5) referring to the Gavard-Sundaram Cohesivity Scale [20]. Results were reported as the mean score $\pm \mathrm{SD}$.

\subsection{Biological Evaluation \\ 4.3.1. Cell Cultures}

A human dermal fibroblast cell line immortalized with hTERT (HDF cells, BJ-5ta, ATCC CRL-4001) was cultured in a 4:1 mixture of Dulbecco's Modified Eagle Medium (DMEM) and Medium199 supplemented with $0.01 \mathrm{mg} / \mathrm{mL}$ hygromycin B and 10\% $(v / v)$ FBS. All materials for HDF culture were purchased from Gibco and Invitrogen. The cells were grown on tissue culture plates using an incubator with a humidified atmosphere $(95 \%$ air $\left./ 5 \% \mathrm{CO}_{2} v / v\right)$ at $37^{\circ} \mathrm{C}$.

\subsubsection{Cell Viability (MTT Test)}

MTT test was accomplished according to La Gatta et al., 2018. Briefly, cells were seeded at a density equal to $2 \cdot \times 10^{4}$ cells $/ \mathrm{cm}^{2}$ in 12 wells. Twenty-four hours after seeding, the treatments were added to the medium at $0.16 \% w / w$ concentration. After $24 \mathrm{~h}$ from gels addition, the cells were observed at inverted optical microscope (MO). Then, cell viability was assessed by measuring the reduction of the tetrazolium dye 3-(4,5-dimethylthiazol-2yl)-5-(3 carboxymethoxyphenyl)-2-(4-sulfophenyl)-2H-tetrazolium (MTT). Medium was removed and cells were treated three times with PBS to remove any residual suspended hydrogels before adding the MTT solution. Cell viability in presence of fillers was reported with respect to untreated cells (viability \%).

4.3.3. Type I Collagen (COLIA1), Type IV Collagen (COLIVA1), Elastin (ELS) and Integrins (INT $\alpha 1$ and $\beta 1$ ) mRNA Quantification Using qRT-PCR Analyses

Total RNA was extracted using TRIzol RNA Isolation Reagents (Thermofischer scientific, Waltham, MA USA), and reverse transcribed by Reverse Transcription System Kit (Promega, Milan, Italy). Quantitative real-time polymerase chain reactions (qRT-PCR) were performed in duplicate for all genes of interest using IQ ${ }^{\mathrm{TM}} \mathrm{SYBR}^{\circledR}$ Green Supermix (Bio-Rad Laboratories, Milan, Italy) and internal control (glyceraldehyde-3-phosphate dehydrogenase, (GAPDH) housekeeping gene). Results are expressed as fold change $\left(2^{-\Delta \Delta \mathrm{Ct}}\right.$ method) in treated cells vs. untreated cells (the control), and normalized to transcript levels of housekeeping gene [48]. qRT-PCR was performed using custom primers reported in Table 3. 
Table 3. Primers sequence used for qRT-PCR analyses.

\begin{tabular}{|c|c|c|}
\hline Gene Name (Symbol) & PCR Primer Sequence $5^{\prime}-3^{\prime}$ & Amplicon Length (bp) \\
\hline $\begin{array}{l}\text { Glyceraldehyde3-phosphate } \\
\text { dehydrogenase (GAPDH) }\end{array}$ & $\begin{array}{l}\text { TTCCACGGCACAGTCAA } \\
\text { GCAGGTCAGGTCCACAA }\end{array}$ & 115 \\
\hline Type I collagen (COLIA1) & $\begin{array}{l}\text { CCAGAAGAACTGGTACATCA } \\
\text { CCGCCATACTCGAACTGGAA }\end{array}$ & 103 \\
\hline Type IV collagen (COLIVA1) & $\begin{array}{l}\text { GGATCGGCTACTCTTTTGTGATG } \\
\text { AAGCGTTTGCGTAGTAATTGCA }\end{array}$ & 104 \\
\hline Elastin (ELS) & $\begin{array}{l}\text { AGGTGTATACCCAGGTGGCGTGCT } \\
\text { CAACCCCTGTCCCTGTTGGGTAAC }\end{array}$ & 105 \\
\hline$\alpha-1$ integrin (INT $\alpha 1)$ & $\begin{array}{l}\text { TCGCCAGCTTTGGAAGTCAT } \\
\text { ATGTACTGGAGTTGGGCAGC }\end{array}$ & 108 \\
\hline$\beta$-1integrin (INT $\beta 1)$ & $\begin{array}{l}\text { ACTGTGATGCCGTATATTAGCAC } \\
\text { GATATGCGTTGCTGACCAACA }\end{array}$ & 110 \\
\hline
\end{tabular}

\subsubsection{Western Blotting for Collagen Type 1, Elastin, and Actin}

Western blotting analyses were performed after $48 \mathrm{~h}$ of treatment. Cells were lysed in Radio-Immunoprecipitation Assay (RIPA buffer 1×; Cell Signaling Technology) and intracellular protein concentration was determined through the Bradford method. Specifically, $30 \mu \mathrm{g}$ of proteins for each sample were resolved on a 10\% SDS-PAGE gel and transferred onto nitrocellulose membrane (GE, Amersham, UK). Then, the membrane was blocked by $5 \%$ non-fat milk in Tris-buffered saline and $0.05 \%$ Tween-20 (TTBS) for $30 \mathrm{~min}$ and primary antibodies against Elastin (Santa Cruz, Dallas, TX, USA), Col I (Elabscience, Houston, TX, USA) and Col IV (Abcam, Cambridge, UK) were diluted 1:500 and incubated overnight at 4 ${ }^{\circ} \mathrm{C}$. Secondary antibodies horseradish peroxidase-conjugated donkey anti-mouse and goat anti-rabbit were diluted 1:5000 and incubated for $2 \mathrm{~h}$ at room temperature. Anti- $\beta$-Actin antibody used at 1:1000 dilution was used as the loading control. The signal was detected using the ECL system (Chemicon-Millipore, Milano, Italy) and the semi-quantitative analyses of protein expression were carried out with the ImageJ program.

\subsection{Statistical Analysis}

Unless otherwise indicated, each experiment was performed at least in triplicate and results are reported as the mean value \pm standard deviation. Data were statistically evaluated by performing One-way ANOVA tests followed by post hoc correction for multiple comparison. The level of significance was fixed at 0.05 .

\section{Conclusions}

Biophysical and biochemical parameters were derived for three crosslinked HA-based gels proposed for intradermal injection as skinboosters. Collected data indicated $\mathrm{H}_{B}$ as the gel with the highest concentration in insoluble HA and the longer soluble HA chains and with the highest water uptake, suggesting deeper hydration properties. $\mathrm{H}_{\mathrm{B}}$ showed the lowest rigidity/viscosity and the highest cohesivity. $\mathrm{J}_{\mathrm{V}}$ was found to be the most resistant to degradation by ROS while longer permanence in the presence of BTH was recorded for $\mathrm{H}_{\mathrm{B}}$. HA-based samples determined a significant improvement of matrix biomarkers expression at the transcriptional level and strong upregulation of integrins was found for $\mathrm{J}_{\mathrm{V}}$ and $\mathrm{H}_{\mathrm{B}}$ treated fibroblasts. However, Western blotting analyses showed only a slight boosting effect of gels on Human Dermal Fibroblasts in terms of Col IV/Col I and elastin production.

Comparison with conventional volumetric formulations revealed differences far lower than expected in relation to composition, hydration capacity and biochemical effects. However, except for $\mathrm{R}_{\mathrm{V}}$, rigidity was decisively lower indicating higher deformability as the most important requirement for more superficial implantation. 
These results are thought to be useful to practitioners for improving the use of these gels and valuable to adjust gel design towards even more specific performance.

Supplementary Materials: The following are available online at https:/ / www.mdpi.com/article/10 $.3390 /$ ijms22116005/s1.

Author Contributions: Conceptualization, A.L.G. and C.S.; methodology, A.L.G., C.S., A.D., A.S., E.B., V.V.; validation, A.L.G. and C.S. for the biophysical analyses, A.S., V.V. and C.S. for biomarker expression and A.D. and C.S. for cytotoxicity tests; investigation, A.L.G., M.A., A.D., A.S., V.V., E.B.; resources, C.S.; data curation, A.L.G., C.S.; writing-A.L.G., C.S., A.S., A.D., G.B., V.V., E.B.; original draft preparation, A.L.G.; writing-review and editing, A.L.G., G.B., A.S., C.S.; supervision, A.L.G., C.S.; project administration, C.S.; funding acquisition, C.S. All authors have read and agreed to the published version of the manuscript.

Funding: Financial support for this research was obtained through Invitalia project, Altergon"Contratto di Sviluppo" CDS 000463 and also BioTekNet (Centro Regionale di Competenza in Biotecnologie Industriali) S.C.p.A.supported a short term grant.

Acknowledgments: The authors would like to express their deepest gratitude to Anna Virginia Adriana Pirozzi, Rosanna Salzillo, Claudia Catalano and Maria Assunta Frezza for their precious support in the initial experimentation on this type of hydrogels.

Conflicts of Interest: G.B. is an employee of IBSA Farmaceutici Italia; the other authors declare no conflict of interest.

\section{References}

1. Ave, M.N.; de Almeida Issa, M.C. Hyaluronic Acid Dermal Filler: Physical Properties and Its Indications. In Botulinum Toxins, Fillers and Related Substances. Clinical Approaches and Procedures in Cosmetic Dermatology; Issa, M., Tamura, B., Eds.; Springer: Cham, Switzerland, 2018; Volume 4, pp. 187-197.

2. Fallacara, A.; Manfredini, S.; Durini, E.; Vertuani, S. Hyaluronic acid fillers in soft tissue regeneration. Facial. Plast. Surg. 2017, 33, 87-96. [CrossRef] [PubMed]

3. Cui, Y.; Wang, F.; Voorhees, J.J.; Fisher, G.J. Rejuvenation of Aged Human Skin by Injection of Cross-linked Hyaluronic Acid. Plast. Reconstr. Surg. 2021, 147, 43S-49S. [CrossRef] [PubMed]

4. Basta, S.L. Cosmetic fillers perspective on the industry. Facial. Plast. Surg. Clin. N. Am. 2015, 23, 417-421. [CrossRef]

5. Heitmiller, K.; Ring, C.; Saedi, N. Rheologic properties of soft tissue fillers and implications for clinical use. J. Cosmet. Dermatol. 2021, 20, 28-34. [CrossRef]

6. Moillard, S.G.; Betemps, J.B.; Hadjab, B.; Topchian, D.; Micheels, P.; Salomon, D. Key rheological properties of hyaluronic acid fillers: From tissue integration to product degradation. Plast. Aesthet. Res. 2018, 5, 17-24. [CrossRef]

7. La Gatta, A.; Salzillo, R.; Catalano, C.; D’Agostino, A.; Pirozzi, A.V.A.; De Rosa, M.; Schiraldi, C. Hyaluronan-based hydrogels as dermal fillers: The biophysical properties that translate into a "volumetric" effect. PLoS ONE 2019, $14, \mathrm{e} 0218287$.

8. La Gatta, A.; De Rosa, M.; Frezza, M.A.; Catalano, C.; Meloni, M.; Schiraldi, C. Biophysical and biological characterization of a new line of hyaluronan-based dermal fillers: A scientific rationale to specific clinical indications. Mater. Sci. Eng. C Mater. Biol. Appl. 2016, 68, 565-572. [CrossRef]

9. Allemann, I.B.; Baumann, L. Hyaluronic acid gel (Juvederm) preparations in the treatment of facial wrinkles and folds. J. Clin. Interv. Aging 2008, 3, 629-634.

10. Muhn, C.; Rosen, N.; Solish, N.; Bertucci, V.; Lupin, M.; Dansereau, A.; Weksberg, F.; Remington, B.K.; Swift, A. The evolving role of hyaluronic acid fillers for facial volume restoration and contouring: A Canadian overview. Clin. Cosmet. Investig. Dermatol. 2012, 5, 147-158. [CrossRef]

11. Borrell, M.; Leslie, D.B.; Tezel, A. Lift capabilities of hyaluronic acid fillers. J. Cosmet. Laser Ther. 2011, 13, 21-27. [CrossRef] [PubMed]

12. Raspaldo, H. Volumizing effect of a new hyaluronic acid sub-dermal facial filler: A retrospective analysis based on 102 cases. Cosmet. Laser Ther. 2008, 10, 134-142. [CrossRef] [PubMed]

13. Jones, D. Volumizing the Face with Soft Tissue Fillers. Clin. Plastic. Surg. 2011, 38, 379-390. [CrossRef] [PubMed]

14. Sundaram, H.; Cassuto, D. Biophysical characteristics of hyaluronic acid soft-tissue fillers and their relevance to aesthetic applications. Plast. Reconstr. Surg. 2013, 132, 5S-21S. [CrossRef]

15. La Gatta, A.; Schiraldi, C.; Papa, A.; De Rosa, M. Comparative analysis of commercial dermal fillers based on crosslinked hyaluronan: Physical characterization and in vitro enzymatic degradation. Polym. Degrad. Stab. 2011, 96, 630-636. [CrossRef]

16. Falcone, S.J.; Berg, R.A. Crosslinked hyaluronic acid dermal fillers: A comparison of rheological properties. J. Biomed. Mater. Res. Part A 2008, 87, 264-271. [CrossRef]

17. Edsman, K.; Nord, L.I.; Ohrlund, A.; Larkner, H.; Kenne, A.H. Gel properties of hyaluronic acid dermal fillers. Dermatol. Surg. 2012, 38, 1170-1179. [CrossRef] 
18. Edsman, K.L.M.; Ohrlund, A. Cohesion of hyaluronic acid fillers: Correlation between cohesion and other physicochemical properties. Dermatol. Surg. 2018, 44, 557-562. [CrossRef]

19. Sundaram, H. Going with the flow: An overview of soft tissue filler rheology and its potential clinical applications (2of 3). Cosmet. Chall. 2011, 23-28.

20. Sundaram, H.; Rohrich, R.J.; Liew, S.; Sattler, G.; Talarico, S.; Trévidic, P.; Molliard, S.G. Cohesivity of Hyaluronic Acid Fillers: Development and Clinical Implications of a Novel Assay, Pilot Validation with a Five-Point Grading Scale, and Evaluation of Six U.S. Food and Drug Administration-Approved Fillers. Plast. Reconstr Surg. 2015, 136, 678-686. [CrossRef]

21. La Gatta, A.; Schiraldi, C.; Zaccaria, G.; Cassuto, D. Hyaluronan Dermal Fillers: Efforts Towards a Wider Biophysical Characterization and the Correlation of the Biophysical Parameters to the Clinical Outcome. Clin. Cosmet. Investig. Dermatol. 2020, $13,87-97$. [CrossRef]

22. Sparavigna, A.; La Gatta, A.; Bellia, G.; La Penna, L.; Giori, A.M.; Vecchi, G.; Tenconi, B.; Schiraldi, C. Evaluation of the Volumizing Performance of a New Volumizer Filler in Volunteers with Age-Related Midfacial Volume Defects. Clin. Cosmet. Investig. Dermatol. 2020, 13, 683-690. [CrossRef] [PubMed]

23. Kablik, J.; Monheit, G.D.; Yu, L.P.; Chang, G.; Gershkovich, J. Comparative physical properties of hyaluronic acid dermal fillers. Dermatol. Surg. 2009, 35, 302-312. [CrossRef]

24. Stocks, D.; Sundaram, H.; Michaels, J.; Durrani, M.J.; Wortzman, M.S.; Nelson, D.B. Rheological evaluation of the physical properties of hyaluronic acid dermal fillers. J. Drugs Dermatol. 2011, 10, 974-980.

25. La Gatta, A.; Salzillo, R.; Catalano, C.; Pirozzi, A.V.A.; D'Agostino, A.; Bedini, E.; Cammarota, M.; De Rosa, M.; Schiraldi, C. Hyaluronan-based hydrogels via ether-crosslinking: Is HA molecular weight an effective means to tune gel performance? Int. J. Biol. Macromol. 2020, 144, 94-101. [CrossRef] [PubMed]

26. Sito, G. Hydrolift Action: A New Approach in Facial Reshaping. IBSA Hyaluronic Acid Experts. Available online: prime-journal. com (accessed on 25 March 2013).

27. Arsiwala, S.Z. Current trends in facial rejuvenation with fillers. J. Cutan. Aesthet. Surg. 2015, 8, 125-126. [CrossRef]

28. Kerscher, M.; Buntrock, H.; Hund, M.; Mokosch, A.; Ogilvie, A.; Samimi-Fard, S.; Waibel, M. Restylane ${ }^{\circledR}$ Skinboosters $^{\mathrm{TM}}$ for the improvement of the skin quality-Results of a consensus meeting. Cosmet. Med. 2017, 17, 28-34.

29. Niforos, F.; Ogilvie, P.; Cavallini, M.; Leys, C.; Chantrey, J.; Safa, M.; Abrams, S.; Hopfinger, R.; Marx, A. VYC-12 Injectable Gel Is Safe and Effective for Improvement of Facial Skin Topography: A Prospective Study. Clin. Cosmet. Investig. Dermatol. 2019, 12, 791-798. [CrossRef]

30. Beatini, A.; Piersini, P.; Russo, R. "REAL LIFE" efficacy evaluation of a new hyaluronic acid gel suitable for deep hydration and fine wrinkles correction. Aesthetic Med. J. 2019, 5, 19-24.

31. Viscoderm Hydrobooster ${ }^{\circledR}$ [Package Insert]; RosePharma S.A.: Lugano, Switzerland, 2019.

32. Juvederm Volite ${ }^{\circledR}$ [Package Insert]; Allergan: Pringy, France, 2019.

33. Restylane ${ }^{\circledR}$ Skinboosters ${ }^{T M}$ Vital; Q-Med AB: Uppsala, Sweden, 2019.

34. D'Agostino, A.; Stellavato, A.; Corsuto, L.; Diana, P.; Filosa, R.; La Gatta, A.; De Rosa, M.; Schiraldi, C. Is molecular size a discriminating factor in hyaluronan interaction with human cells? Carbohyd. Polym. 2017, 157, 21-30. [CrossRef] [PubMed]

35. Urdiales-Gálvez, F.; Delgado, N.E.; Figueiredo, V.; Lajo-Plaza, J.V.; Mira, M.; Moreno, A.; Ortíz-Martí, F.; Del Rio-Reyes, R.; Romero-Álvarez, N.; Del Cueto, S.R.; et al. Treatment of Soft Tissue Filler Complications: Expert Consensus Recommendations. Aesthetic Plast. Surg. 2018, 42, 498-510. [CrossRef]

36. Beasley, K.L.; Weiss, M.A.; Weiss, R.A. Hyaluronic acid fillers: A comprehensive review. Facial. Plast. Surg. 2009, 25, 86-94. [CrossRef]

37. Sundaram, H.; Fagien, S. Cohesive Polydensified Matrix Hyaluronic Acid for Fine Lines. Plast. Reconstr. Surg. 2015, 136 (Suppl. 5), 149-163. [CrossRef]

38. Stern, R.; Jedrzejas, M. Hyaluronidases: Their genomics, structures, and mechanism of action. Chem. Rev. 2006, 106, 818-838. [CrossRef] [PubMed]

39. Sall, I.; Ferard, G. Comparison of the sensitivity of 11 crosslinked hyaluronic acid gels to bovine testis hyaluronidase. Polym. Degrad. Stabil. 2007, 92, 915-919. [CrossRef]

40. La Gatta, A.; De Rosa, M.; Marzaioli, I.; Busico, T.; Schiraldi, C. A complete hyaluronan hydrodynamic characterization using a size exclusion chromatography-triple detector array system during in vitro enzymatic degradation. Anal Biochem. 2010, 404, 21-29. [CrossRef] [PubMed]

41. Pérez-Sánchez, A.; Barrajón-Catalán, E.; Herranz-López, M.; Micol, V. Nutraceuticals for Skin Care: A Comprehensive Review of Human Clinical Studies. Nutrients 2018, 10, 403. [CrossRef] [PubMed]

42. Shin, J.W.; Kwon, S.H.; Choi, J.Y.; Na, J.I.; Huh, C.H.; Choi, H.R.; Park, K.C. Molecular Mechanisms of Dermal Aging and Antiaging Approaches. Int. J. Mol. Sci. 2019, 20, 2126. [CrossRef] [PubMed]

43. El-Domyati, M.; Attia, S.; Saleh, F.; Brown, D.; Birk, D.E.; Gasparro, F.; Ahmad, H.; Uitto, J. Intrinsic aging vs. photoaging: A comparative histopathological, immunohistochemical, and ultrastructural study of skin. Exp. Dermatol. 2002, 11, 398-405. [CrossRef] [PubMed]

44. de Filippis, A.; D'Agostino, A.; Pirozzi, A.V.A.; Tufano, M.A.; Schiraldi, C.; Baroni, A. Q-switched Nd-YAG laser alone and in combination with innovative hyaluronic acid gels improve keratinocytes wound healing in vitro. Lasers Med. Sci. 2020. [CrossRef] 
45. Manou, D.; Caon, I.; Bouris, P.; Triantaphyllidou, I.E.; Giaroni, C.; Passi, A.; Karamanos, N.K.; Vigetti, D.; Theocharis, A.D. The Complex Interplay Between Extracellular Matrix and Cells in Tissues. Methods Mol. Biol. 2019, 1952, 1-20.

46. Moulin, V.; Plamondon, M. Differential expression of collagen integrin receptor on fetal vs. adult skin fibroblasts: Implication in wound contraction during healing. Br. J. Dermatol. 2002, 147, 886-892. [CrossRef]

47. Donejko, M.; Rysiak, E.; Galicka, E.; Terlikowski, R.; Głażewska, E.K.; Przylipiak, A. Protective influence of hyaluronic acid on focal adhesion kinase activity in human skin fibroblasts exposed to ethanol. Drug Des. Devel. Ther. 2017, 11, 669-676. [CrossRef] [PubMed]

48. Stellavato, A.; Corsuto, L.; D’Agostino, A.; La Gatta, A.; Diana, P.; Bernini, P.; De Rosa, M.; Schiraldi, C. Hyaluronan Hybrid Cooperative Complexes as a Novel Frontier for Cellular Bioprocesses Re-Activation. PLoS ONE 2016, 11, e0163510. [CrossRef] [PubMed] 